losophy for graduate training in Agricultural and Home Economics Extension Administration at the University of Wisconsin encourages the kind of flexibility that allows programs to be designed for the needs of the individual student. This is true in the National Center as well as in the Departments of Agricultural and Extension Education and Home Economics Education and Extension. It does mean more faculty time is needed to work with students.
The students in the National Agricultural Extension Center for Advanced Study are at $W$ isconsin to improve themselves in their jobs in the Agricultural and Home Economics Extension Service. The objectives of the program are carried out by careful individual attention to the students' course work and his research. The national character of the Center which in 1957-58 includes students from 21 different states, Hawaii and Alaska, provides an ideal setting.

\title{
COMMUNITY INFLUENCES AND ADULT LEARNING
}

By Howard Y. McClusky

Director, Bureau of Studies and Training in Community Adult Education, University of Micbigan

A Community is people. At least the distinguishing feature of the human community is people. Factories, stores, houses, schools, churches and playgrounds without people are a shell and not a community.

If a community is people the objective of a community is people. The community is a means and intermediate while people are ends and ultimate. Community development may, therefore, be described as the development of people by the development of the community.

A community is external and internal. It is a place. It has institutions, laws, services. These are external. It is also a common holding of attitudes and values and an experience of togetherness. These are internal. It is conceivably possible to have each with little of the other. But in a complex urban society this is very unlikely to occur. In a world such as ours the external fact and the inner experience of community are interrelated and highly interdependent.

Let us now turn pedagogical and look briefly at how the local (or "home") community influences adult learning. The community is a gate to the adult as a learner. It is the primary setting for most of his basic experiences of living. Here he works, plays, suffers, dreams and dies. Here the outside world makes its greatest impact on his personal life, and largely from what he learns here, he, in turn, constructs his private view of the outside world. In other words, the "home" community provides most of the apperceptive mass and most of the 
rewards and punishments which shape his incentive and resistance to learning.

There is another and a more specific sense in which the community provides a gate to the adult as a learner. All communities have formal and informal systems of communication and practically all adults are tied up with or belong to one or more of these systems. If we can delineate the system to which an adult belongs and locate his place in it, we have gone a long way toward gaining access to his willingness to learn. On the other hand, if we do not know the system to which he belongs, he is lost to our stimulation in what appears to our confused observation as a maze of patternless interaction-lost regardless of his ripeness and need for learning, and regardless of the inherent attractiveness of what we have to offer.

One cue to location in the communication network is the position of an adult in the social structure. If he is upper middle this suggests one kind of network, if he is upper lower it suggests another.

Another cue to network location is affiliation with organized groups. Non-membership indicates the probability of communication through chains of informal association while both the number and kinds of groups to which he belongs suggests the likelihood of communication through more visible and ordered lines of interaction. Formal and informal networks often overlap and either separately or in combination may yield revealing sociometric data. But whether he is upper middle or upper lower; whether he is caught up in formal or informal orbits of association or both; and wherever he may appear in a sociometric map, it is important to know that an adult occupies a special position in some system of communication in the community in which he lives, and that this knowledge may provide valuable insight concerning his accessibility and readiness for learning.

The community is also educative. While analogies are often misleading, let us think of the community as a teacher and the members of the community as its pupils. In a literal sense we learn what we live. Since the community provides most of the ways by which we live it is to that extent a teacher. For example it teaches us habits of safety and sanitation, ways of making a living and using our leisure time, and ways of handling political, economic and racial conflict. These and similar items might be called the implicit curriculum of community life.

Libraries, schools, museums, and newspapers contain the explicit curriculum of the educative community.

Less obvious, but possibly more influential, is the educational role of all agencies and persons in a community with an educative potential. A factory could undertake an interpretation of its place in the economy of a community. Realtors could educate the public to build beauty and usefulness into the layout of commercial, manufacturing and residential properties.

Law enforcement officials could discover the causes of delinquency and educate the community with a view to their elimination. The fact that these and other elements of the community rarely exercise their educational role, does not in the least de- 
tract from the value of their doing so.

To continue our theme: if the community is a teacher, and if community development is our objective, it follows that we should educate the community to become a better teacher. And if the community is people we must educate people to produce a better community. Thus in educating the community the adult would educate himself and in educating people for community development we would be educating people for community self-help. Every teacher will tell you that the best way to learn a subject is to teach it.

What abilities and knowledge must an adult possess to perform these educative tasks? To suggest a few: First, he should be able to help a community size up the nature of its problem, state it clearly, and determine the extent of agreement concerning his diagnosis. Second, he should be able to gather information about the problem, either by getting facts on his own, or by calling on those who are especially knowledgeable about the issues involved. Third, he should be able to locate and make use of the resources which are available for the solution of the problems which he confronts. Fourth, he should be able to view problems in the perspective of the whole community and over a long enough period of time to include the relevant past and the forseeable future. And fifth, in all these activities he should be able to understand conflicts and keep them within manageable bounds.

The foregoing abilities are illustrative of the equipment required by the educative adult, and, in effect, suggest a part of what might be called the curriculum for the education of adults in community development.

If space permitted we could test the validity of the preceding argument by applying it to the development of a community through strengthening its economy, improving its health, or by pointing out how a community may keep constructively ahead of the recurring demands for expanding community services. These are elements of the external community. But as stated earlier, there is also an internal community. This, too, can be an object of community development. For example, we could educate a community to deal productively with economic and racial conflict. This would involve the ventilation of anxieties and the development of acceptance based on understanding. Again, we could develop the community of the spirit so that people would achieve greater dignity and meaning in their personal lives. This would deal with such items as the problem of suffering and the great affirmations of the human adventure as portrayed by art, music, literature, history and religion.

To be concrete: a community council for the enrichment of the mind and spirit of the community would be just as relevant for community development as a community council for the development of the economy. The object of both would be to build up both the external and internal environment of the community in order to increase the political, social, economic, and spiritual autonomy of its members. Both would require educative processes for educational goals, and both, it is hoped, would lead to the development of the educative adult in the educative community. 